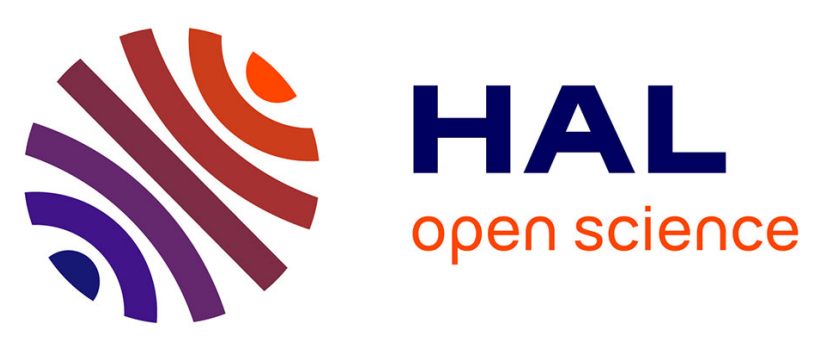

\title{
Surfactant-modifications of Na+-beidellite for the preparation of TiO2-Bd supported photocatalysts: I-organobeidellite precursor for nanocomposites
}

Benaïssa Rhouta, Lahcen Bouna, Francis Maury, François Senocq, Marie-Christine Lafont, Amane Jada, M’Barek Amjoud, Lahcen Daoudi

\section{To cite this version:}

Benaïssa Rhouta, Lahcen Bouna, Francis Maury, François Senocq, Marie-Christine Lafont, et al.. Surfactant-modifications of Na+-beidellite for the preparation of $\mathrm{TiO} 2-\mathrm{Bd}$ supported photocatalysts: I-organobeidellite precursor for nanocomposites. Applied Clay Science, 2015, 115, pp.260-265. 10.1016/j.clay.2015.04.024 . hal-01264362

\section{HAL Id: hal-01264362 \\ https://hal.science/hal-01264362}

Submitted on 7 Mar 2016

HAL is a multi-disciplinary open access archive for the deposit and dissemination of scientific research documents, whether they are published or not. The documents may come from teaching and research institutions in France or abroad, or from public or private research centers.
L'archive ouverte pluridisciplinaire HAL, est destinée au dépôt et à la diffusion de documents scientifiques de niveau recherche, publiés ou non, émanant des établissements d'enseignement et de recherche français ou étrangers, des laboratoires publics ou privés. 


\section{Open Archive TOULOUSE Archive Ouverte (OATAO)}

OATAO is an open access repository that collects the work of Toulouse researchers and makes it freely available over the web where possible.

This is an author-deposited version published in : http://oatao.univ-toulouse.fr/ Eprints ID : 14590

To link to this article : DOI:10.1016/j.clay.2015.04.024

URL : http://dx.doi.org/10.1016/j.clay.2015.04.024

To cite this version : Rhouta, Benaïssa and Bouna, Lahcen and Maury, Francis and Senocq, François and Lafont, Marie-Christine and Jada, Amane and Amjoud, M'barek and Daoudi, Lahcen Surfactant-modifications of $\mathrm{Na+-}$ beidellite for the preparation of $\mathrm{TiO2}-\mathrm{Bd}$ supported photocatalysts: Iorganobeidellite precursor for nanocomposites. (2015) Applied Clay Science, vol.115. pp.260-265. ISSN 0169-1317

Any correspondance concerning this service should be sent to the repository administrator: staff-oatao@listes-diff.inp-toulouse.fr 


\title{
Surfactant-modifications of $\mathrm{Na}^{+}$-beidellite for the preparation of $\mathrm{TiO}_{2}$-Bd supported photocatalysts: I-organobeidellite precursor for nanocomposites
}

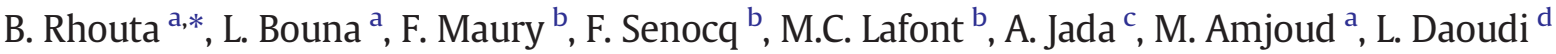 \\ a Laboratoire de Matière Condensée et Nanostructures (LMCN), Faculté des Sciences et Techniques Guéliz, Université Cadi Ayyad, BP 549 Marrakech, Morocco \\ b CIRIMAT, Université de Toulouse, CNRS-UPS-INP, ENSIACET, 4 allée Emile Monso, BP 44362, 31030 Toulouse, cedex 4, France \\ c Institut de Sciences des Matériaux de Mulhouse (IS2M), LRC 7228 - CNRS, 15 rue Jean Starcky, BP 2488, 68057 Mulhouse cedex, France \\ ' Laboratoire Geoscience et Géoenvironnement, Faculté des Sciences et Techniques Guéliz, Université Cadi Ayyad, BP 549, Marrakech, Morocco
}

Keywords:

Beidellite

Smectite

Surfactant

Organoclay

Intercalation

Expansion

\section{A B S T R A C T}

This study aims at determining suitable conditions for the preparation of the best organobeidellite starting material used for the development of efficient mesoporous $\mathrm{TiO}_{2}$ supported beidellite (Bd) photocatalysts. For this purpose, organo-modifications of natural Bd from Agadir Basin (Morocco) were achieved. The influence of (i) the length of alkyl chains $\mathrm{C}_{\mathrm{n}}\left(\mathrm{n}=8,12,14\right.$ and 16) of $\mathrm{n}$-alkyl ammonium surfactants $\mathrm{CH}_{3}\left(\mathrm{CH}_{2}\right)_{\mathrm{n}-1} \mathrm{NH}_{3}^{+}$and (ii) the amount of $\mathrm{C}_{16}$ surfactant ranging from 1 to 5 times the smectite $(\mathrm{Sm})$ cation exchange capacity (CEC) on the structure of organo- Bd was studied. XRD, TEM, TG-DTA and FTIR results are consistent with the intercalation of cationic surfactants species in Bd interlayer spaces according to different conformations yielding to their expansion. The interlayer expansion magnitude increased both with the length of alkyl chain and the amount of $\mathrm{C}_{16}$ surfactant. Organomodification with increasing surfactant load beyond 1CEC besides yielded to the adsorption of increasing excess on external surfaces of Bd particles. These controlled structural modifications will be used further in the functionalization of this $\mathrm{Bd}$ by $\mathrm{TiO}_{2}$ nanoparticles to produce efficient supported $\mathrm{TiO}_{2}-\mathrm{Bd}$ photocatalysts.

\section{Introduction}

Clay minerals, especially those of the smectite (Sm) family, are involved in a wide array of applications owing to, besides their natural abundance and low costs, their specific properties such as high cation exchange capacity (CEC), swelling ability, high surface areas and subsequently strong adsorption capacities (Velde, 1995; Bergaya and Lagaly, 2006). Nevertheless, their uses remain limited due to their hydrophilicity related to the presence of hydrated interfoliaceous inorganic cations within their structure that stems from ionic substitutions in their tetrahedral and/or octahedral sheets (Velde, 1995; Bergaya and Lagaly, 2006). They can be rendered hydrophobic by several routes amongst which the exchange of interlayer inorganic cations with organic ones, currently alkylammoniums, which furthermore result in the expansion of their interlamellar spaces (Lagaly, 1986; Lagaly and Dékany, 2005).

These features permit to develop a new class of derivative materials, namely organoclays, which have new versatile innovative applications as adsorbents of organic pollutants (de Paiva et al., 2008; Liu et al.,

\footnotetext{
* Corresponding author.

E-mail address: b.rhouta@uca.ma (B. Rhouta).
}

2008; Park et al., 2011), rheological control agents (Manias et al., 1996), refractory varnish (de Paiva et al., 2008), thixotropic agent in coating and thickener in ink (Beall, 2003), component in the development of clay polymer nanocomposites (CPN) (Alexandre and Dubois, 2000; Ray and Okamoto, 2003), template in the preparation of graphite film (Isayama et al., 1996) or of mesoporous inorganic heterostructures (Letaief et al., 2006). In these applications, the behavior and properties of the organoclays are strongly related to the structure and the molecular environment of the intercalated cationic organic species within the silicates interlayer spaces. In this respect, depending on the amount and the kind of the surfactant (mono-, di- or tri-alkyl, chain length...) and on the nature of clay mineral (chemical composition of the sheets, layer charge and its distribution...), cationic surfactant entities could be packed inside interlamellar spaces in the form of lateral mono-, bior pseudo tri-layer, or even of paraffin mono- or bi-layer (Lagaly, 1986; Lagaly and Dékany, 2005; Bouna et al., 2011 and 2013).

In the case of CPN, it was reported that the synthesis of the material exhibiting the best properties required organoclay precursor with the largest basal spacing (Vaia et al., 1994; Lagaly et al., 2006). As far as inorganic heterostructured materials are concerned, several works reported the immobilization of $\mathrm{SiO}_{2}$ nanoparticles on montmorillonite (Mt) (Letaïef et al., 2006) or of $\mathrm{TiO}_{2}$ nanoparticles on Mt (An et al., 
2008), sepiolite (Aranda et al., 2008; Gómez-Avilés et al., 2013; Ruiz-Hitzky and Aranda, 2014), palygorskite (Bouna et al., 2011 and 2013) as supported photocatalysts starting from the corresponding organoclays. In such syntheses, the linear alkyl ammonium surfactant (cetyltrimetylammonium ion, namely $\mathrm{C}_{16}$ ) amount used was equivalent to 3 times the cation exchange capacity (CEC) of the clay mineral. It was suggested that the surfactant acts as a template affording organophilic environment favorable to hydrolysis and condensation of organometallic reagents of Ti or Si (Letaïef et al., 2006; Aranda et al., 2008) and it could be quite completely removed once $\mathrm{TiO}_{2}$ or $\mathrm{SiO}_{2}$ nanoparticles respectively are formed without disturbing photocatalytic activity (Aranda et al., 2008; Bouna et al., 2011). It is worth mentioning that no systematic studies were reported on the effects of alkyl chain length or surfactant load both on the microstructure of immobilized oxide (average size and distribution of oxide nanoparticles) onto clay mineral particles and on the photoactivity of the $\mathrm{TiO}_{2}$-clay supported photocatalysts.

Organoclays involved in beforehand mentioned applications were mostly prepared starting from Mt which is a Mg-for-Al octahedrally substituted end member of dioctahedral Sm series (Lee and Kim, 2002). He et al (2006) reported that the reaction between a given surfactant and montmorillonites from different occurrences, therefore exhibiting variable chemical compositions inducing different layer charge, i.e different CEC, yielded structurally different organoclays.

More recently, mineralogical, physico-chemical, textural and structural properties of an abundant Bd -rich clay deposit from Agadir basin (Morocco) were reported (Bouna et al., 2012). Bd is different from Mt in that it is an end member of dioctahedral Al- Sm with an average layer charge of 0.6 to 0.7 pretty completely created by the substitution of $\mathrm{Si}^{4+}$ by $\mathrm{Al}^{3+}$ in the tetrahedral positions (Nadeau et al., 1985). The Bd -rich clay is considered herein as starting material to prepare convenient organobeidellite precursors as first step for the synthesis of efficient $\mathrm{TiO}_{2}$-supported $\mathrm{Bd}$ photocatalysts. The photocatalytic activity will be further optimized by controlling the microstructural features, i.e. size and distribution of $\mathrm{TiO}_{2}$ nanoparticles onto clay mineral particles.

This paper aims at studying the effects of the length of alkyl chain and load of cationic surfactant on the structure of derivative organobeidellite that will be used as precursor for the synthesis of $\mathrm{TiO}_{2}$-beidelitte supported photocatalysts. It will be extended by a companion paper focusing on microstructural and photocatalytic properties resulting from these controlled structural changes. In addition, such organobeidellites could be employed as starting materials for the development of other kinds of oxide/Bd- or polymer/clay- nanocomposites.

\section{Experimental}

\subsection{Starting materials}

Organomodified Bd were prepared starting from $12 \mu \mathrm{m} \mathrm{Na}{ }^{+}$ exchanged $\mathrm{Bd}$ fine fraction $\left(\mathrm{Na}^{+}-\mathrm{Bd}\right)$, isolated according to the procedure described elsewhere (Rhouta et al., 2008; Bouna et al., 2012), from the raw clay (Bd) sampled from the region of western high Atlas basin of Agadir (Morocco). The raw clay and corresponding purified $\mathrm{Na}^{+}-$ exchanged clay fraction were previously characterized in details (Bouna et al., 2012). The $\mathrm{Na}^{+}$-exchanged $\mathrm{Bd}$ is composed of $93 \%$ of $\mathrm{Bd}$, and $7 \%$ of kaolinite (Kaol). Its CEC, BET specific surface area, and total pore volume are respectively around $59.7 \mathrm{mEq} / 100 \mathrm{~g}, 82.2 \mathrm{~m}^{2} / \mathrm{g}$ and $0.136 \mathrm{~cm}^{3} /$ $\mathrm{g}$. The structural formula of Bd was determined after subtraction of Kaol contribution as $\left(\mathrm{Si}_{7.51} \mathrm{Al}_{0.49}\right)\left(\mathrm{Al}_{2.99} \mathrm{Fe}_{0.68} \mathrm{Mg}_{0.33}\right)\left(\mathrm{Ca}_{0.03} \mathrm{Na}_{0.54} \mathrm{Mg}_{0.11}\right) \mathrm{O}_{20}$ $(\mathrm{OH})_{4}$. It shows dioctahedral aluminiferous features with a structural negative layer charge per half-unit-cell of about 0.41 e created by $60 \%$ and $40 \%$ of isomorphic substitutions in tetrahedral and octahedral sheets respectively.

Linear alkyl chain ammonium bromide compounds $\left[\mathrm{CH}_{3}\left(\mathrm{CH}_{2}\right)_{\mathrm{n}-}\right.$ $\left.{ }_{1} \mathrm{NH}_{3}\right]^{+} \mathrm{Br}^{-}$, abbreviated $\mathrm{C}_{\mathrm{n}} \mathrm{Br}$, having various alkyl chain lengths ( $\mathrm{n}=$
8, 12, 14 and 16) were purchased from Aldrich and were used as received without further purification.

\subsection{Preparation}

In order to study the effect of alkyl chain length of surfactants on their intercalation within Bd interlayers, specific samples were prepared. Taking into account molar masses of surfactants, an appropriate amount (equivalent to $3 \mathrm{CEC}$ of $\mathrm{Bd}$ considered herein) of these different linear alkyl chain compounds were added to an aqueous dispersion of $\mathrm{Na}^{+}$-exchanged $\mathrm{Bd}(1 \mathrm{wt} \%)$. Likewise, to investigate the influence of surfactant loading on its insertion inside Bd interlayer spaces, increasing amounts of cethyltrimethyl ammonium bromide (CTAB) $\left(\mathrm{C}_{16} \mathrm{H}_{33} \mathrm{NH}_{3} \mathrm{Br}\right)$, equivalent to 1,3 and 5 CEC of the $\mathrm{Sm}$, were added at the ambient temperature to $1 \mathrm{wt} \%$ aqueous dispersion of $\mathrm{Na}^{+}$- Bd. After $48 \mathrm{~h}$ of stirring, these dispersions were centrifuged to recover corresponding solids which were thereafter washed several times with distilled water to remove surfactant excess as evidenced by the absence of foam and finally dried in an oven at $60{ }^{\circ} \mathrm{C}$ for 2 days. The different organomodified $\mathrm{Bd}$ samples as synthesized were designated according to the chain length $(\mathrm{n})$ and amount of surfactant $(\mathrm{x})$ expressed in term of the clay mineral CEC as follows: $\mathrm{xC}_{\mathrm{n}}-\mathrm{Bd}$, where $\mathrm{x}=1,3$ and 5 and $\mathrm{n}=8,12,14$ and 16 atoms of carbon.

\subsection{Characterizations}

The expansion degree of Bd layers upon organomodification was evaluated by XRD analyses in small angle range $\left(1 \leq 2 \theta \leq 10^{\circ}\right)$ where the 001 basal reflection is expected and also examining corresponding thin foils by transmission electron microscopy. XRD patterns were recorded using a Seifert XRD 3000TT apparatus $\left(\mathrm{Cu} \mathrm{K}_{\alpha 1+\alpha 2}\right)$ radiation, equipped with a diffracted beam graphite monochromator in the Bragg-Brentano configuration. Microstructural observations were performed with a Jeol JEM 2010 transmission electron microscope (TEM) equipped with an energy dispersive X-ray Tracor analyzer (EDS). A small amount of material powder was first dispersed in ethanol with an ultrasonic bath. After that, droplets of this dispersion were placed on a copper grid ( $3 \mathrm{~mm}$ in diameter) covered by a thin layer of amorphous carbon. After evaporation of ethanol, particles of the sample were retained on the grid which was introduced in the TEM apparatus using a sample holder.

The presence of functional groups characterizing surfactants in organomodified Bd was checked out by Fourier Transformed infrared (FTIR) spectroscopy. Spectra were recorded using a Nicolet 5700 spectrometer under ambient conditions in the frequency range 400$4000 \mathrm{~cm}^{-1}$ using $\mathrm{KBr}$ pellets. The pellets contained a mixture of $2 \mathrm{mg}$ of clay material with $198 \mathrm{mg}$ of $\mathrm{KBr}(\sim 1 \mathrm{wt} \%)$.

The amount of surfactant retained by Bd upon organomodification was assessed by thermal analysis. The thermogravimetric (TG) and Differential Thermal Analysis (DTA) thermograms were collected using a Setaram Labsys apparatus on sample masses of about $60 \mathrm{mg}$ and using a temperature ramp of $10^{\circ} \mathrm{C} / \mathrm{min}$ from the ambient to $1000^{\circ} \mathrm{C}$.

The chemical compositions $\mathrm{CHN}$ of starting $\mathrm{Na}^{+}-\mathrm{Bd}$ as well as derivative organobeidellites $\left(3 \mathrm{CTA}^{+}-\mathrm{Bd}\right.$ and $\left.5 \mathrm{CTA}^{+}-\mathrm{Bd}\right)$ were determined by using Perkin Elmer 2400 Series II apparatus.

\section{Results and discussion}

\subsection{Effect of the length of alkyl chain}

Fig. 1 represents XRD patterns of starting $\mathrm{Na}^{+}$-exchanged $\mathrm{Bd}\left(\mathrm{Na}^{+}{ }_{-}\right.$ $\mathrm{Bd}$ ) and its modification with an amount equivalent to 3 CEC of surfactants differing in their alkyl chain lengths (n). It shows the shift of the characteristic 001 basal reflection of the Bd towards low angles upon organomodification, i.e towards larger $\mathrm{d}_{001}$ values. The shift is increasing with $\mathrm{n}$. Indeed, the basal distance $\mathrm{d}_{001}$, initially at $1.25 \mathrm{~nm}$ in 


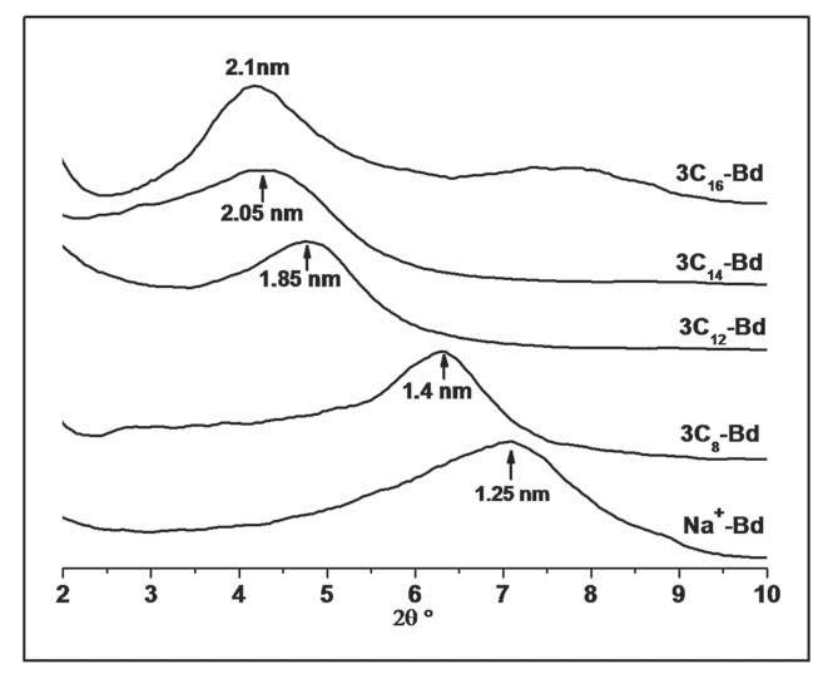

Fig. 1. XRD diagrams of $\mathrm{Na}^{+}$-exchanged Bd before and after organomodification with surfactants differing in the length of alkyl chains.

unmodified $\mathrm{Bd}$, is found at $1.40,1.85,2.05$ and $2.10 \mathrm{~nm}$ upon the organomodification with alkylammoniums composed of $8,12,14$ and 16 carbons, respectively. These results clearly indicate the expansion of Bd interlayer spaces caused by the intercalation of alkylammonium species in these spaces to replace charges compensating $\mathrm{Na}^{+}$interlayer ions. Nevertheless, the difference of expansion degree, observed according to the alkyl chain length of surfactant, denotes that different conformations were adopted by alkylammonium species within $\mathrm{Bd}$ interlayer spaces. These conformations depend on alkylammonium entities packing density, which in turn rely on the surface charge density of clay mineral and the surfactant alkyl chain. In fact, as it was reported in the literature (Lagaly, 1986; Lee and Kim, 2002; Lagaly and Dékany, 2005; de Paiva et al., 2008; Liu et al., 2008; He et al., 2010; Wang et al., 2011), the increase of basal distances from 1.25 to 1.4 and $1.85 \mathrm{~nm}$, upon the clay mineral modification with $C_{8}$ and $C_{12}$ surfactants, respectively, are consistent with the arrangement of entities of these surfactants inside Bd interlayer spaces in the form of a monolayer and a bilayer, respectively. On the other hand, the intercalation of $C_{14}$ and $\mathrm{C}_{16}$ surfactants resulted in quite the same expansion of Bd layers to approximately $2.1 \mathrm{~nm}$. This degree of expansion denotes that both the surfactants might be laid inside $\mathrm{Bd}$ interlayer spaces as pseudo trimolecular layer or monolayer of paraffin (Lagaly, 1986; Lagaly and Dékany, 2005; de Paiva et al., 2008; Hu et al., 2013). Nevertheless, it was reported that ammonium groups are best accommodated to oxygen atoms of clay mineral

basal surfaces when they are involved in paraffin monolayer than in pseudo trimolecular layer (de Paiva et al., 2008). In this respect, an expansion magnitude $\Delta \mathrm{d}$ of $1.13 \mathrm{~nm}$ was assessed by subtracting the

Table 1

Structural data determined from XRD analysis for two series of organobeidellites $\mathrm{xC}_{\mathrm{n}}-\mathrm{Bd}$ differing by chain length of the surfactant ( $\mathrm{n}$ ) and the amount of CTAB surfactant (x).

\begin{tabular}{|c|c|c|c|c|c|}
\hline $\mathrm{n}$ & $\mathrm{x}$ & $\begin{array}{l}\mathrm{d}_{001} \\
(\mathrm{~nm})\end{array}$ & $\begin{array}{l}\text { Expansion } \\
\Delta \mathrm{d}(\mathrm{nm})\end{array}$ & $\begin{array}{l}\mathrm{CTA}^{+} \text {arrangement } \\
\text { mode }\end{array}$ & $\begin{array}{l}\text { Tilt angle } \\
\alpha\left({ }^{\circ}\right)\end{array}$ \\
\hline \multicolumn{6}{|c|}{ Effect of surfactants chains lengths ( $n$ ) } \\
\hline 8 & 3 & 1.40 & 0.43 & Monolayer & - \\
\hline 12 & 3 & 1.85 & 0.88 & Bilayer & - \\
\hline 14 & 3 & 2.05 & 1.08 & Parrafin monolayer & 25 \\
\hline 16 & 3 & 2.10 & 1.13 & Paraffin monolayer & 27 \\
\hline \multicolumn{6}{|c|}{ Effect of CTAB surfactant loads in term of $x C E C$} \\
\hline 16 & 1 & 1.73 & 0.76 & monolayer & - \\
\hline 16 & 2 & 2.10 & 1.13 & Paraffin monolayer & 27 \\
\hline 16 & 3 & 2.10 & 1.13 & Paraffin monolayer & 27 \\
\hline 16 & 5 & 3.90 & 2.93 & Paraffin bilayer & 37 \\
\hline
\end{tabular}

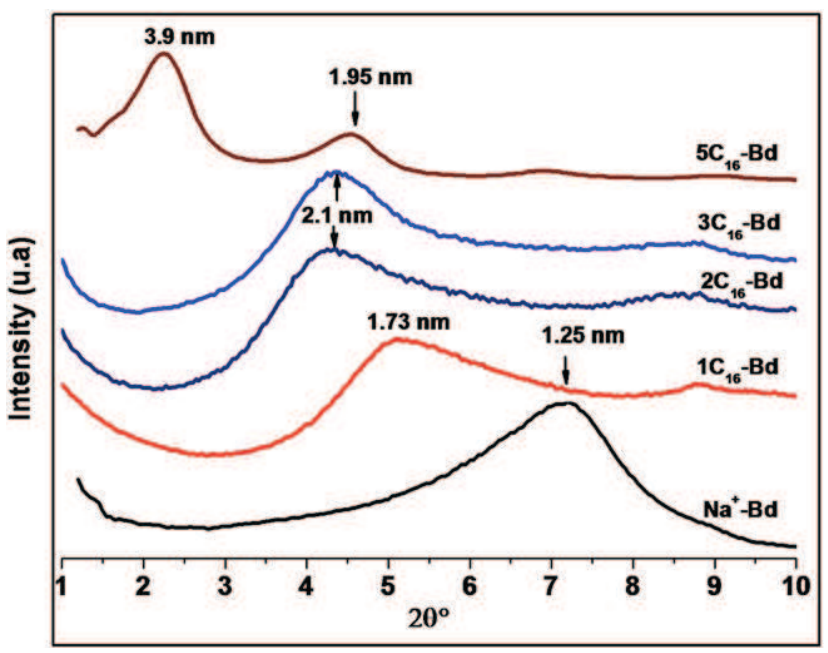

Fig. 2. XRD diagrams superposition of $\mathrm{Na}^{+}$-exchanged $\mathrm{Bd}$ before and after organomodification with different amounts of CTAB surfactant.

layer thickness of Sm $(\approx 0.97 \mathrm{~nm})$ (He et al., 2006) from the basal distance $2.1 \mathrm{~nm}$ beforehand mentioned. Knowing that the alkyl chain length (l) of $\mathrm{C}_{16}$ surfactant molecule (CTAB) is $2.53 \mathrm{~nm}$ (He et al., 2006), it can be deduced from the Eq. (1) (Lagaly, 1986; Lagaly and Dékany, 2005; He et al., 2006) that entities of this surfactant are tilted within interlayer spaces of an inclination angle $(\alpha)$ of almost $27^{\circ}$ with respect to Bd basal surfaces:

$\alpha=\sin ^{-1}(\Delta d / l)$

Table 1 gathers basal distances assessed from XRD analysis for a series of organobeidellites versus chain length ( $\mathrm{n}$ ) of the surfactants used, corresponding caused expansion magnitudes and the arrangement mode of their species between Bd layers.

\subsection{Effect of $C_{16}$ surfactant amount}

Owing to the high expansion generated by the $C_{16}$ surfactant, the study was carried out by examining the effect of the load of this surfactant on the structure of organobeidellite derivatives.

XRD diffractograms of $\mathrm{Bd}$ modified with different amounts of $\mathrm{C}_{16}$ surfactant expressed as a multiple of CEC reveals that the initial 001 basal reflection of $\mathrm{Bd}$ at $1.25 \mathrm{~nm}\left(2 \theta=7.2^{\circ}\right)$ is shifted to smaller angles

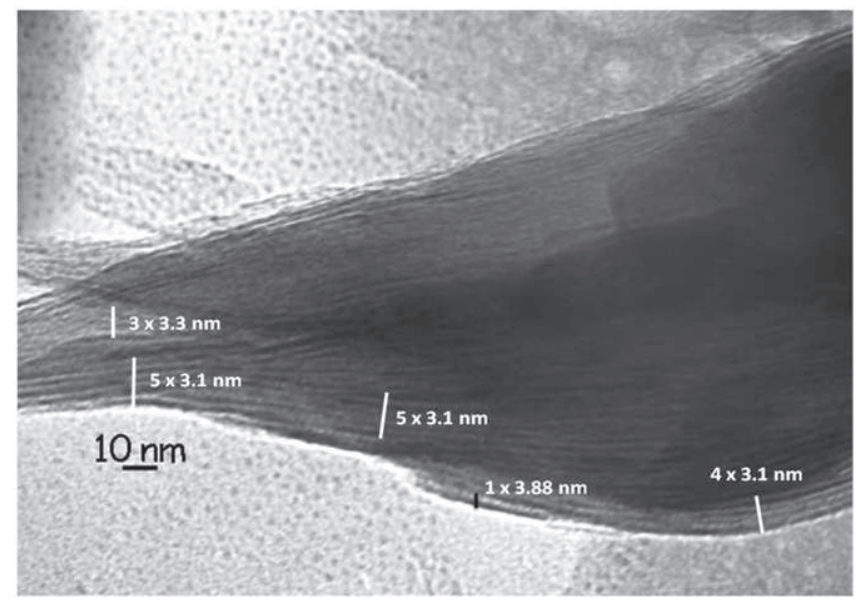

Fig. 3. TEM micrograph showing different basal distances of Bd organomodified with an amount of the CTAB surfactant equivalent to 5 CEC. 


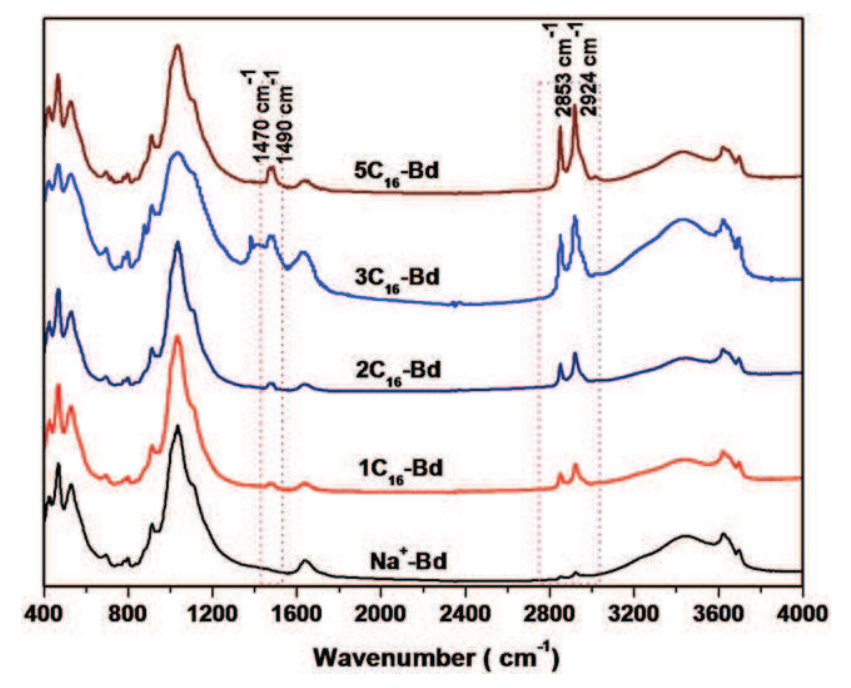

Fig. 4. Infrared spectra of $\mathrm{Na}^{+}$-Bd before and after organomodification with different amounts of the CTAB surfactant.

and thus to higher basal spacing $\mathrm{d}_{001}$ as the amount of the surfactant increased (Fig. 2). Indeed, upon the modification with an amount equivalent to $1 \mathrm{CEC}$, the $\mathrm{d}_{001}$ distance increased from 1.25 to $1.73 \mathrm{~nm}$ $\left(2 \theta=5.1^{\circ}\right)$. Likewise, the modification with amounts equivalent to 2 and 3 CEC yields to a same increase of the basal distance to about $2.1 \mathrm{~nm}\left(2 \theta=4.3^{\circ}\right)$. By contrast, the Bd organomodified with an amount equivalent to 5 CEC exhibits the 001 basal reflection at $3.9 \mathrm{~nm}(2 \theta=$ $\left.2.2^{\circ}\right)$ along with harmonics (002) at $1.95 \mathrm{~nm}\left(2 \theta=4.6^{\circ}\right)$ and $(003)$ at $1.27 \mathrm{~nm}\left(2 \theta=6.95^{\circ}\right)$.

These results prove the success of intercalation of the surfactant alkylammonium between Bd layers resulting in the expansion of interlayer spaces. Higher is the amount of the surfactant, higher is the expansion degree. It is worth noting that the 001 basal reflection in samples organomodified with concentrations of CTAB equivalent to 1 , 2 and 3 CEC appears less resolved, asymmetric, less intense and broader. Owing to the heterogeneous distribution of layer charge characterizing Sm (Lagaly and Dékany, 2005), this could originate from random rearrangement of cationic species of the surfactant inside Bd interlayer spaces yielding to inhomogeneous Bd layers with some different basal spacings. Thus, the distances assessed above may represent an average of irregular distances of spacings. Nevertheless, the sample obtained upon organomodification with CTAB concentration equivalent to 5 CEC exhibited 001 reflection relatively thinner, more symmetric and with a better resolution. This indicates an ordered structure of CTA ${ }^{+}$ species in Bd interlayer spaces yielding to a better homogeneity of layers in this sample.

Dimensional characteristics regarding the molecular conformation of CTAB were reported in details by He et al (2006). As a free molecule, it is characterized by a fixed length of the "nail" about $2.53 \mathrm{~nm}$, consisting of the "nail-head" $(0.43 \mathrm{~nm})$ and "nail-body" $(2.1 \mathrm{~nm})$. Nevertheless, the height of the $\mathrm{CTA}^{+}$differs according to its orientation. Indeed, when the plane of the zigzag arrangement of the carbon atoms of $\mathrm{CTA}^{+}$is perpendicular to the plane of the silicate layer, the height of the "nail-body" is $\approx 0.46 \mathrm{~nm}$ and that of the "nail-head" is $\approx 0.51 \mathrm{~nm}$. On the other hand, when the plane of the zigzag arrangement of CTA carbon skeleton is parallel to the plane of the clay mineral layer, the heights of "nail-body" and "nail-head" are $0.41 \mathrm{~nm}$ and $0.67 \mathrm{~nm}$, respectively. By taking into account these data, the magnitude order of interlayer expansion caused by $1 \mathrm{CEC}$ of $\mathrm{CTAB}(\Delta \mathrm{d} \approx 0.76 \mathrm{~nm})$ is rather likely consistent with the height of the "nail-head" of cationic surfactant species when they are arranged in the form of monolayer lying parallel to the plane of Bd layers. This finding is in contrast to that reported by He et al (2006) for Mt from China. The interlayer expansion resulting from modification with $3 \mathrm{CEC}(\Delta \mathrm{d} \approx 1.13 \mathrm{~nm})$ indicates that surfactant entities form monolayer paraffin structure with a tilt angle of about $27^{\circ}$. Upon organomodification with 5 CEC, Bd interlayer spaces were expanded of about $\Delta \mathrm{d} \approx 2.93 \mathrm{~nm}$ indicating that surfactant species likely formed bilayer paraffin structure with tilt angle of about $37^{\circ}$.

Table 1 recapitulated basal distances recorded from XRD analysis upon organomodification of Bd by increasing amount of CTAB, corresponding expansion degree and the disposition mode of its entities within Bd interlayer spaces.

TEM micrograph of the most organomodified Bd sample $\left(5 \mathrm{C}_{16^{-}} \mathrm{Bd}\right)$ is shown in Fig. 3. It exhibits the expansion of Bd interlayer spaces as evidenced by interlayer distances ranging from 3.1 to $3.9 \mathrm{~nm}$ which proved surfactant intercalation. It is worth noting that the dispersion of these distances is narrow so that it likely denotes a quite homogeneous intercalation of CTAB surfactant whose species seemed to be well ordered within $\mathrm{Bd}$ interlayer spaces in agreement with the above XRD data. FTIR spectroscopy carried out on the different organomodified Bd samples (Fig. 4) shows, besides bands characteristic of Bd (Bouna et al., 2012), that higher is the surfactant amount, more intense are the symmetric and asymmetric stretching vibrations at 2924 and $2853 \mathrm{~cm}^{-1}$, respectively. These spectra also show their corresponding deformation vibrations at 1490 and $1470 \mathrm{~cm}^{-1}$, which are the fingerprint of CTAB surfactant species.

Furthermore, thermal analysis, performed on different organomodified $\mathrm{Bd}$ samples based on $\mathrm{C}_{16}$ surfactant investigated herein, reveals for temperature ranging from 200 to $750^{\circ} \mathrm{C}$, mass losses on TG thermograms (Fig. 5a) associated to exothermic effects on DTA curves (Fig. 5b), due to the thermal degradation of CTAB surfactant. These organic mass losses increased with the amount of the used organo-modifying
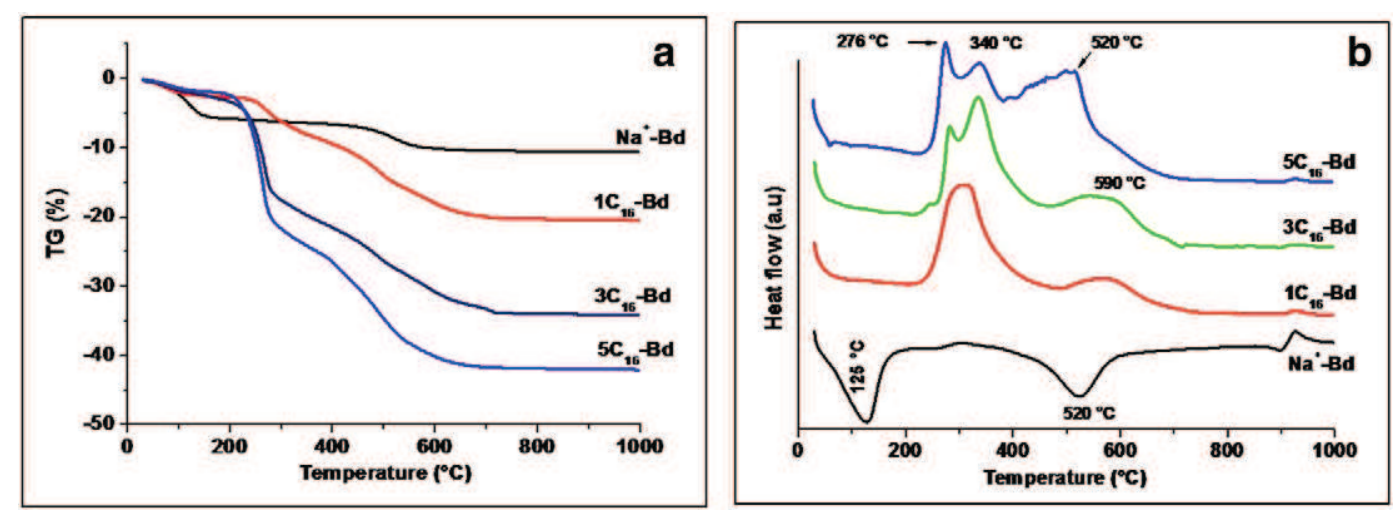

Fig. 5. TG (a) and DTA (b) Thermograms of $\mathrm{Na}^{+}$-Bd before and after organomodification with different amounts of CTAB surfactant. 
Table 2

Comparison between experimental organic losses recorded in the temperature range $\left[200-750^{\circ} \mathrm{C}\right]$ upon thermal analysis performed on $\mathrm{Na}^{+}$-beidellite organomodified with different amounts of CTAB surfactant and theoretical ones calculated according to the Eq. (2).

\begin{tabular}{lll}
\hline & Experimental organic loss (wt \%) & Theoretical organic loss (wt \%) \\
\hline 1 CEC & 14 & 14.2 \\
3 CEC & 28 & 33.0 \\
5 CEC & 37 & 45.2 \\
\hline
\end{tabular}

agent (Table 2). These experimental losses are quite consistent with those theoretically predicted from Eq. (2) taking into account the $\mathrm{x}$ times

CEC used of the Bd (herein, $\mathrm{x}=3$ ) and molar mass of the surfactant cation ( $\mathrm{M}_{\mathrm{CTA}}^{+}$) (Wang et al., 2011) (Table 2):

$$
\begin{aligned}
Q_{C T A+}= & \left\lfloor\left(x C E C \times M_{C T A+} \times 10^{-3}\right) /\left(x C E C \times M_{C T A+} \times 10^{-3}+100\right)\right\rfloor \\
& \times 100 \%
\end{aligned}
$$

These results were further supported by CHN analysis. Indeed, findings reported in Table 3 showed that while the mass contents of $C, H$ and $\mathrm{N}$ elements were as expected quite negligible in unmodified beidellite $\left(\mathrm{Na}^{+}-\mathrm{Bd}\right)$, they however increased in derivative organoclays $\left(3 \mathrm{CTA}^{+}{ }_{-}\right.$ $\mathrm{Bd}$ and $5 \mathrm{CTA}^{+}-\mathrm{Bd}$ ) with the increase of CTAB loads used for beidellite organomodification. Taking into account the chemical formula of the CTAB on one hand and the CEC $(\approx 60 \mathrm{meq} / 100 \mathrm{~g})$ of the beidellite on the other hand, the amounts of $\mathrm{C}, \mathrm{H}$ and $\mathrm{N}$ corresponding to the complete exchange of beidellite interlayer $\mathrm{Na}^{+}$ions with $\mathrm{CTA}^{+}$entities can be deduced as equivalent to 10,2 and $1 \mathrm{wt} \%$ respectively. These amounts were lower than those determined by $\mathrm{CHN}$ analysis of $3 \mathrm{CTA}^{+}$-Bd and $5 \mathrm{CTA}^{+}$-Bd. This likely denoted that while a sufficient same part of $\mathrm{CTA}^{+}$was intercalated in beidellite interlayer spaces according to arrangements established above for $3 \mathrm{CTA}^{+}$-Bd and $5 \mathrm{CTA}^{+}$-Bd organoclays to compensate the totality of permanent layers charges, the excess of CTAB was probably adsorbed outside on external surfaces of $B d$ particles. It seems that this excess of $C T A B$ is higher in $5 \mathrm{CTA}^{+}$-Bd with respect to $3 \mathrm{CTA}^{+}$-Bd.

\section{Conclusions}

This study aimed at examining the behavior of an aluminiferous Bd from Agadir basin, Morocco, toward organomodification with linear alkyl chain ammonium surfactants in the objective to use these organobeidellite precursors for the further preparation of efficient $\mathrm{TiO}_{2}$ supported $\mathrm{Bd}$ photocatalysts. The study of the influence of the length of the alkyl chain of surfactant shows that the best expansion of Bd interlayer spaces is achieved with surfactants whose carbon atoms number is beyond 14 . The study of the influence of the amount of $\mathrm{CTA}^{+}$(i.e surfactant composed of $16 \mathrm{C}$ ) shows that the concentration of 1 CEC, 3 CEC and 5 CEC leads to an arrangement of $\mathrm{CTA}^{+}$species inside Bd interlayer spaces in the form of monolayer perpendicular to the plane of clay mineral, paraffin monolayer and paraffin bilayer, respectively oriented according to tilt angles of about 27 and $37^{\circ}$, respectively. Not intercalated surfactant excess, which was higher

Table 3

Mass contents of $\mathrm{C}, \mathrm{H}$ and $\mathrm{N}$ elements in unmodified $\mathrm{Na}^{+}$-exchanged beidellite $\left(\mathrm{Na}^{+}-\mathrm{Bd}\right)$ and its derivative organobeidellites $\left(3 \mathrm{CTA}^{+}\right.$-Bd and $5 \mathrm{CTA}^{+}$-Bd).

\begin{tabular}{llll}
\hline $\begin{array}{l}\text { Elements } \\
\text { Samples }\end{array}$ & $\mathrm{C}($ wt\%) & $\mathrm{H}(\mathrm{wt} \%)$ & $\mathrm{N}(\mathrm{wt} \%)$ \\
\hline $\mathrm{Na}^{+}-\mathrm{Bd}$ & & & \\
$3 \mathrm{CTA}^{+}-\mathrm{Bd}$ & 0.3 & 1.2 & 0.1 \\
$5 \mathrm{CTA}^{+}-\mathrm{Bd}$ & 20.0 & 4.0 & 1.2 \\
\hline
\end{tabular}

when using amount equivalent to 5CEC than 3CEC, was adsorbed on external surfaces of Bd particles.

This practical and useful study is continued in a companion paper that reports the influence of these structurally different organobeidellites, i.e. $3 \mathrm{CTA}^{+}-\mathrm{Bd}$ and $5 \mathrm{CTA}^{+}-\mathrm{Bd}$, on the microstructure of $\mathrm{TiO}_{2}$ (crystalline phase, particles size and distribution) supported on $\mathrm{Bd}$, and thus on the photocatalytic activity of supported $\mathrm{TiO}_{2}$ - $\mathrm{Bd}$ catalyst towards the removal of pollutant from aqueous media.

\section{Acknowledgement}

The financial supports from the "Convention de cooperration CNRSTMaroc/CNRS-France" (chemistry project $\mathrm{N}^{\circ} 04 / 13$ ) and the "Programme d'Action Intégrée Volubilis' ( $\mathrm{N}^{\circ} 14 / \mathrm{SM} / 14$ ) are gratefully acknowledged.

\section{References}

Alexandre, M., Dubois, P., 2000. Polymer-layered silicate nanocomposites: preparation, properties and uses of a new class of materials. Mater. Sci. Eng. 28, 1-63.

An, T., Chen, J., Li, G., Ding, X., Sheng, G., Fu, J., Mai, B., O' Shea, K.-E., 2008. Characterization and photocatalytic activity of $\mathrm{TiO} 2 \mathrm{immobilized} \mathrm{hydrophobic} \mathrm{Mt}$ photocatalysts: Degradation of decabromodiphenyl ether (BDE 209). Catalaysis Today $139,69-76$.

Aranda, P., Kun, R., Martin-Luengo, M.A., Letaïef, S.S., Dékány, I., Ruiz-Hitzky, E., 2008. Titania-sepiolite nanocomposites prepared by a surfactant templating colloidal route. Chem. Mater. 20, 84-91.

Beall, G.W., 2003. The use of organo-clays in water treatment. Appl. Clay Sci. 24 $11-20$.

Bergaya, F., Lagaly, G., 2006. Chapter 1: general introduction: clays, clay minerals, and clay science. In: Bergaya, F., Theng, B.K.G., Lagaly, G. (Eds.), Handbook of clay science, developments in clay science. Ed Elsevier, pp. 1-19.

Bouna, L., Rhouta, B., Amjoud, M., Maury, F., Lafont, M.-C., Jada, A., Senocq, F., Daoudi, L. 2011. Synthesis, characterization and photocatalytic activity of $\mathrm{TiO}_{2}$ supported natural palygorskite microfibers. Appl. Clay Sci. 52, 301-311.

Bouna, L., Rhouta, B., Daoudi, L., Maury, F., Amjoud, M., Senocq, F., Lafont, M.-C., Jada, A. 2012. Mineralogical and physic-chemical characterisations of ferruginous beidellite rich clay from Agadir basin (Morocco). Clay Clay Miner. 60, 278-290.

Bouna, L., Rhouta, B., Maury, F., 2013. Physicochemical study of photocatalytic activity of $\mathrm{TiO}_{2}$ supported palygorskite clay mineral. Int. J. Photoenergy 6 http://dx.doi.org/10. 1155/2013/815473 (Article ID 815473).

de Paiva, L.B., Morales, A.R., Valenzuela Diaz, F.R., 2008. Organoclays: Properties, preparation and applications. Appl. Clay Sci. 42, 8-24.

Gómez-Avilés, A., Aranda, P., Fernandes, F.M., Belver, C., Ruiz-Hitzky, E., 2013. Silica-sepiolite nanoarchitectures. J. Nanosci. Nanotechnol. 13, 2897-2907.

He, H., Frost, R.L., Bostrom, T., Yuang, P., Duong, L., Yang, D., Xi, Y., Kloprogge, J.T., 2006 Changes in the morphology of organoclays with HDTMA $^{+}$surfactant loading. Appl. Clay Sci. 31, 262-271.

He, H., Ma, Y., Zhu, J., Yuan, P., Qing, Y., 2010. Organoclays prepared from montmorillonites with different cation exchange capacity and surfactant configuration. Appl. Clay Sci. 48, 67-72.

Hu, Z., He, G., Liu, Y., Dong, C., Wu, X., Zhao, W., 2013. Effects of surfactant concentration on alkyl chain arrangements in dry and swollen organic montmorillonite. Appl. Clay Sci. 75-76, 134-140.

Isayama, M., Nomiyama, K., Kunitake, T., 1996. Template synthesis of a large, self-supporting graphite film in montmorillonite. Adv. Mater. 8, 641-644.

Lagaly, G., 1986. Interaction of alkylamines with different types of layered compounds. Solid State Ionics 22, 43-51.

Lagaly, G., Dékany, I., 2005. Adsorption on hydrophobized surfaces: Clusters and self-organization. Adv. Colloid Interf. Sci. 114-115, 189-204.

Lagaly, G., Ogawa, M., Dékány, I., 2006. Clay mineral organic interactions, in: Handbook of clay science. Elsevier, Amsterdam, pp. 309-377.

Lee, S.Y., Kim, S.J., 2002. Expansion characteristics of organoclay as a precursor to nanocomposites. Colloids Surf. A Physicochem. Eng. Asp. 211, 19-26.

Letaïef, S., Angeles Martin-Luengo, M., Aranda, P., Ruiz-Hitzky, E., 2006. A colloidal route for delamination of layered solids: Novel porous-clay nanocomposites. Adv. Funct. Mater. 16, 401-409.

Liu, R., Frost, R.-L., Martens, W.-N., Yuan, Y., 2008. Synthesis, characterization of mono, diand tri-alkyl surfactant intercalated Wyoming montmorillonite for the removal of phenol from aqueous systems. J. Colloid Interface Sci. 327, 287-294.

Manias, E., Hadziioannou, G., Brinke, G., 1996. Inhomogeneities in sheared ultrathin lubricating films. Langmuir 12, 4587-4593.

Nadeau, P.H. Farmer, V.-C., McHardy, W.-J., Bain, D.-C., 1985. Compositional variations of the Unterrupsroth beidellite. Am. Mineral. 70, 1004-1010.

Park, Y., Ayoko, G.A., Frost, R.L., 2011. Application of organoclays for the adsorption of 291 recalcitrant organic molecules from aqueous media. J. Colloid Interface Sci. 354 292-305.

Ray, S.S., Okamoto, M., 2003. Polymer/layered silicate nanocomposites: a review from preparation to processing. Prog. Polym. Sci. 28, 1539-1641.

Rhouta, B., Kaddami, H., Elbarqy, J., Amjoud, M., Daoudi, L., Maury, F., Senocq, F. Maazouz, A., Gerard, J.-F., 2008. Elucidating the crystal-chemistry of Jbe 
Rhassoul stevensite (Morocco) by advanced analytical techniques. Clay Miner. 43, 393-404.

Ruiz-Hitzky, E., Aranda, P., 2014. Novel architectures in porous materials based on clays. J. Sol-Gel Sci. Technol. 70, 307-316.

Vaia, R.A., Teukolsky, R.K., Giannelis, E.P., 1994. Interlayer structure and molecular environment of alkylammonium layered silicates. Chem. Mater. 6, 1017-1022.
Velde, B., 1995. Origin and mineralogy of clays: Clays and the environment. SpringerVerlag, Berlin, Heideberg, New York (334 pp.).

Wang, L., Chen, Z., Wang, X., Yan, S., Wang, J., Fan, Y., 2011. Preparation of organovermiculite with large interlayer space by hot solution and ball milling methods: A comparative study. Appl. Clay Sci. 51, 151-157. 